\title{
Farming on the Barcelona fringe
}

Landscape Res. 43, 613-631 (2018)

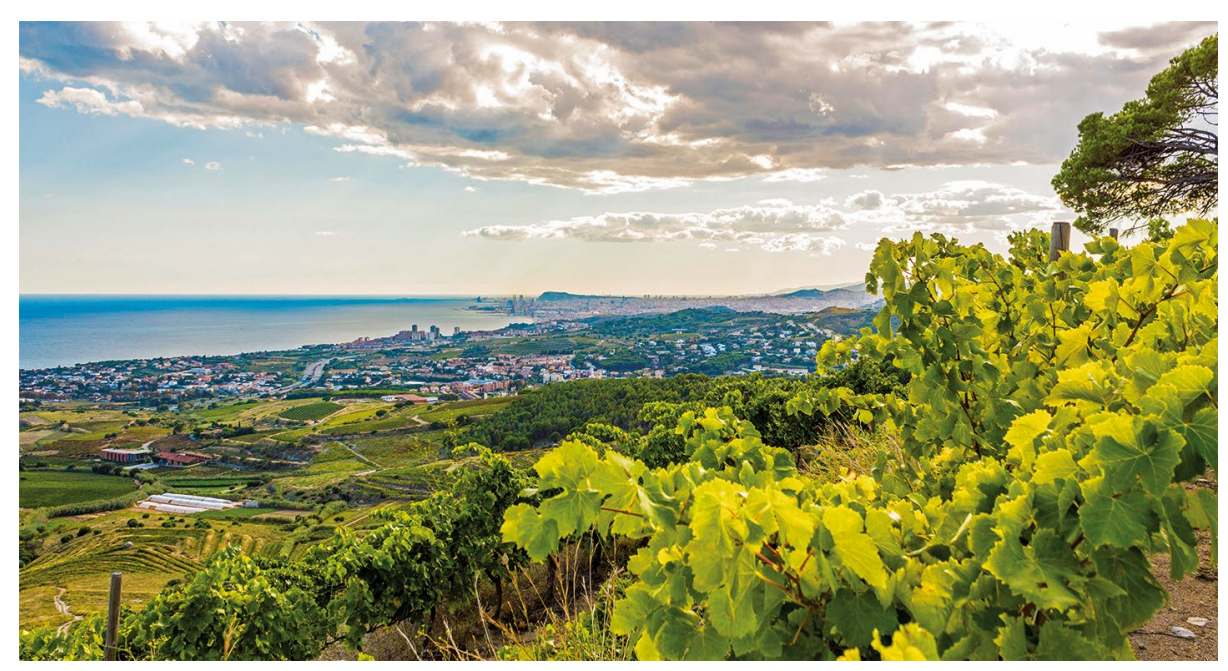

Credit: Hans Geel / Alamy Stock Photo

Land use on the peri-urban fringe can be fraught not just with multiple jurisdictions and zoning regimes, but also with multiple uses that compete with each other and change over time. Agricultural uses caught in the path of urbanization have been tracked and studied, but until now there has been little effort to connect those uses to wider socioenvironmental contexts.

Pere Serra, at the Universitat Autònoma de Barcelona, and colleagues compared two detailed images of the Barcelona area in Catalonia from 1957 and 2009, creating typologies of land use around the metropolitan area using 24 variables, from building and population size to age of the farmers. The typology was then based on scores that incorporated factors such as agricultural activity, economic value, ecological protection and the socioenvironmental function.

Between 1957 and 2009, the peri-urban area around Barcelona lost $63 \%$ of its cropland to urbanization, resulting in fragmentation of agricultural space and an increase in the number of patches that fulfill various uses and types of agriculture. The highest value typology, based on socio-environmental functions, is in the forests of Baix Llobregat, although the lack of young farmers to replace the older generation puts this area at risk along with many others. Nonetheless, such land serves not only to retain biodiversity, but also acts as a restraint on further sprawl.

\section{Ryan Scarrow}

Published online: 5 June 2018

https://doi.org/10.1038/s41477-018-0181-2 